\title{
The Effect of Knowledge Management Systems on Measuring Success Indicators for Saudi Arabia 2030
}

\author{
Bader A. Alyoubi ${ }^{1}$ \\ ${ }^{1}$ Department of Management Information Systems, College of Business, University of Jeddah, Jeddah, Saudi Arabia \\ Correspondence: Bader A. Alyoubi, Department of Management Information Systems, College of Business, \\ University of Jeddah, Jeddah, Saudi Arabia.
}

Received: October 24, 2019

Accepted: November 15, 2019

Online Published: December 22, 2019

doi:10.5430/rwe.v10n4p31

URL: https://doi.org/10.5430/rwe.v10n4p31

\begin{abstract}
Vision 2030 is designed to place the Kingdom of Saudi Arabia (KSA) as a trading and financial hub in the Middle East. Ninety-six strategic objectives are framed for Vision 2010. Whilst these objectives are very inspiring, challenges are seen in integrating them under a single unifying framework. Unless the diverse objectives are integrated, knowledge and learning of team members are brought on a common platform to measure the success indicators, achieving the vision would be difficult. Objective of the paper is to develop a KM model that will help to measure the success indicators of Vision 2030. A literature review helped to understand the barriers, processes, and methodology of KM frameworks. The findings indicate that Vision 2030 is wide in scope with 96 loosely connected strategic objectives. An overarching framework that links all these objectives and places them on a common platform is not evident. These inputs were used to design the KM Vision 2030 model that links all the objectives and helps to gather metrics from the objectives, and measure the success of the project. Some of the metrics that can be considered are linking objectives, milestone achievement, adhering to schedule and budget, economic and social impact on people and businesses, progress in positioning KSA as the leader of Middle East, and others. Some of these measures are qualitative, whilst others are quantitative, implying that a multimodal data collection and analysis method is needed. The model suggests institution of Knowledge Champions, Communities of Practice, big data analytics, knowledge assets development and sharing, and brings all the objectives on a transparent and usable platform. A pilot study in the form of a semi-structured interview and survey was administered to five experts in the field of KM and IT systems. Their findings indicate that big data analytics can play a major role in decision-making and in measuring the project success. The findings also speak of the need to connect the strategic objectives. Recommendations are made to refine the model.
\end{abstract}

Keywords: Vision 2030, KM for Vision 2030, Big Data for Vision 2030, integrating objectives, metrics to measure success

\section{Introduction}

Knowledge Management (KM) is a structured process to create, share, and deploy the learning and knowledge in an organisation. KM is internal facing in the sense that efforts are taken to improve the intellectual capital of a firm through internal sources and through external inputs. (Hislop, D., Bosua, R. \& Helms, R., 2018) According to Chang and Lin, (Jansen, W., 2017) the basic concept of KM is that an organisation and its employees gain expertise and implicit or explicit skills that are documented and shared through the KM platform. Other employees can use these documented learning to shorten the learning curve and anticipate and resolve problems faster, thus helping to increase the productivity and success of the firm. Jansen (2017) asserts that KM is an enabling tool, it helps to collect and disburse knowledge, and it does not directly increase the firm's success. Thus, it is important to establish the KM objectives and link it to organisational objectives. The objective of the paper is to develop a KM model that will help to measure the success indicators of Vision 2030.

The paper is structured as follows. A brief description of the research problem is followed by an analysis of Vision 2030. A literature review is presented with an analysis of KM frameworks for governments and KM implementation in governments. Using inputs from the previous sections, a Vision $2030 \mathrm{KM}$ model is presented that is expected to answer the research problem. A methodology section presents an instrument used for the pilot primary research, 
respondents, and the method used for analysis. Results of the analysis are presented along with conclusions, recommendations, and suggestions for further study.

\subsection{The Research Problem}

Fakir and Yerkes (2018) are of the opinion that other Arab nations have plans similar to the one proposed by Saudi Arabia. Vision 2030 sees rivals such as Qatar National Vision 2030, Kuwait Vision 2035, and UAE Vision. All these visions and projects have plans for pushing their nation as the hub for non-oil trading centre. Nuruzzaman (2018) is critical of these projects and argues that the dominant theme is to foster the conservative Islamic narratives in the project whilst poor human rights and social uprising scare off potential Western investors. Whilst the Vision 2030 project is well structured and detailed, the challenge is in implementing the strategic objectives where the benefits are realised. The vision has 96 objectives across various and diversified sectors, and it is evident that these objectives are not based on a common platform with common processes, methods, and measures of success.

Tuwaijri (2018) speaks of integrating strategic objectives to provide a comprehensive knowledge-based framework that will link all objectives. It is clear that gathering data on the subjects of various objectives and defining metrics to measure their success becomes critical. Therefore, the research problem is how to create an overarching knowledge management framework that KM can play a role in in developing a repository of learning and advisories that will help to achieve the objectives and measure the success of Vision 2030.

\subsection{About Vision 2030}

Saudi Vision 2030 is a project by Saudi Arabia to diversify the economy into non-oil sectors such as tourism, education, health, infrastructure, finance, recreation, and others. The objective is to promote and position Saudi Arabia as a trade and technology hub of the Middle East. (Vision 2030) Whilst Saudi Arabia is strong economically with an average per capita income of more than $\$ 41,000$, the oil and gas sector contributes about $40 \%$ to the GDP. With oil resources depleting and peak oil becoming a reality in the near future, Saudi Arabia needs other income sources to sustain the economy. (Note 1)

Vision 2030 is built on three pillars and these are a vibrant society, a thriving economy, and an ambitious nation. Three levels of objectives are framed with the third level carrying 96 strategic objectives. These strategic objectives are diversified and cover areas such as development of retail, local manufacturing, tourism, digital economy, religion, logistics, and several others. (Note 2) It is clear that the objectives are diverse and include a number of areas that need to be linked.

\section{Literature Review}

This section reviews the literature on KM and investigates frameworks and case studies where KM is used. The focus will be on government-related implementations.

\subsection{KM Frameworks for Governments}

Whilst the KM process is successfully implemented in a number of firms such as Ford, Toyota, IBM, and others, there is a need to see KM frameworks for governments. Misra et al. (2003) speak of the loose connections in various government ministries and departments that have their own services, products, rules, ministers, budget, and other issues that act as barriers for integrating and linking the functions. As an example, the energy ministry that looks after power and energy, functions independently from the agricultural ministry. However, power and energy are needed by the agricultural sector, whilst the energy sector needs the help of the agricultural ministry to monitor and control theft of power and to set the priorities for the sector.

Webb (2017) speaks of several models available to understand KM framework and these include the APO KM Framework, Frid framework presented by Dr. Frid, People-Process-Technology framework, Integrated KM and BI framework, and others. However, these frameworks focus on specific departments and functions. The existing frameworks and models do not consider the source for inputs and they do not consider data gathering and analysis. Section 3 proposes a KM framework for Vision 2030.

\subsection{KM Implementations in Governments}

Yamazaki (2012) speaks of KM implementation in government functions of countries such as India, Singapore, Korea, Thailand, and Malaysia. The KM practices were focussed on various objectives such as productivity improvement, risk management, improving transparency, and removing silo-like structures, delivering efficient services to citizens, etc. Some level of improvement was observed in meeting the objectives. Substantial gaps remain in integrating all departments and functions. Gupta and Singh (2014) highlight some of the problems of KM 
implementation on government schemes. These include a lack of an overarching vision, less cohesion and ownership, silos and lack of data portability, no analysis of data, and lack of skilled knowledge workers.

\section{Proposed KM Model}

The previous section reviewed the literature on KM frameworks and various case studies on KM implementation. For the Vision 2030, a much broader framework is needed since many objectives are to be covered with a timeline of $10+$ years. (Note 3) Figure 1 presents a conceptual Vision 2030 KM model designed by this researcher.

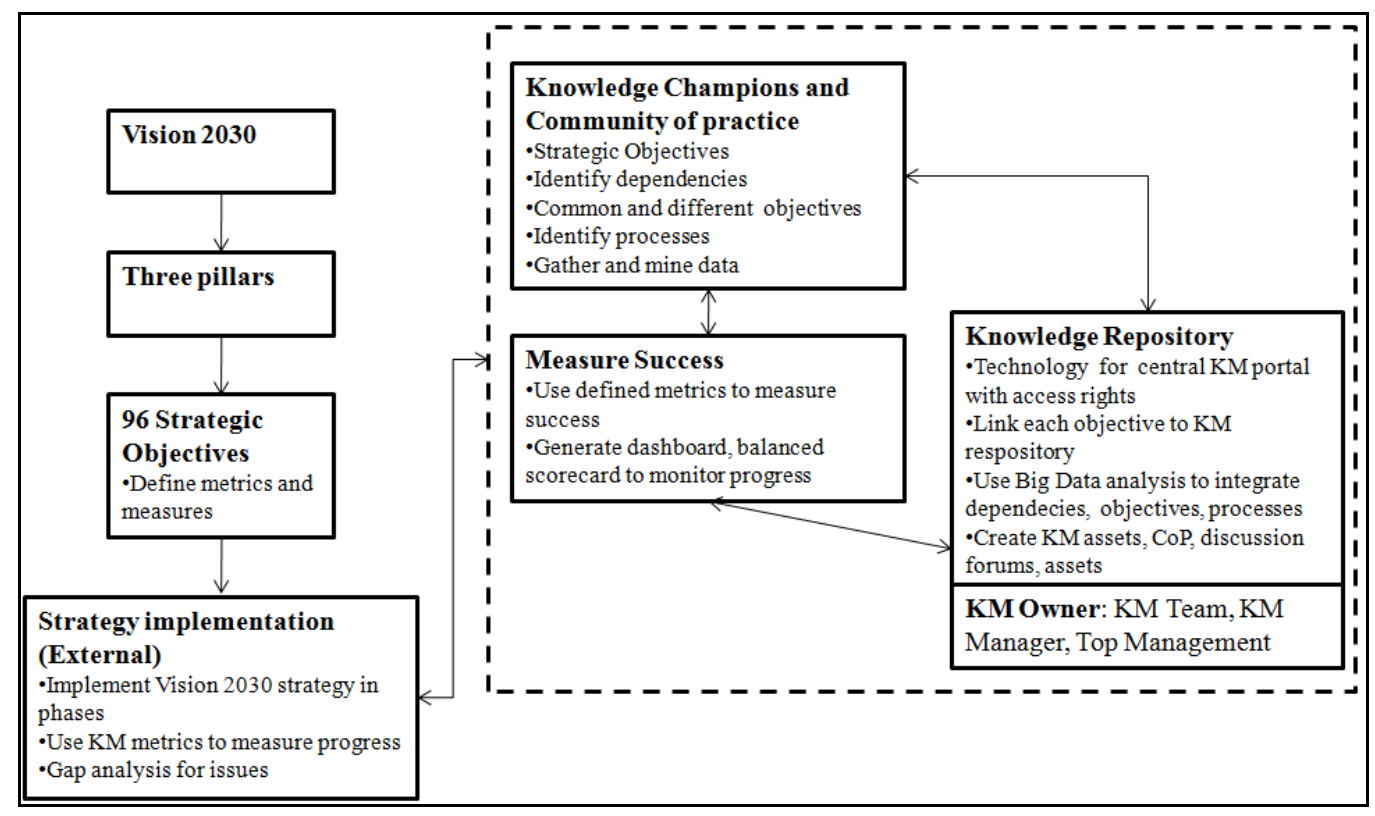

Figure 1. Proposed Vision 2030 KM Framework (Author's Construct)

The left side of the framework represents known elements such as the Vision 2030, the 3 pillars, and the 96 strategic objectives, explained in section 1.2. The middle and the right components relate to the KM Vision 2030. For each strategic objective, it is essential that metrics of performance, results, and success should be defined. The Vision 2030 team specifies these metrics. These are explained as follows.

Knowledge champions and community of practice: Each strategic objective will have at least one knowledge champion who is well versed with the strategic objective, knows the implementation details, and encourages team members to contribute their learning through knowledge documents. Community of practice (CoP) is an informal group of people working on the same domain who interact with each other through discussion forums, group meetings, webinars, and other information dissemination practices. (Geisler, E. \& Wickramasinghe, N., 2015) The groups along with the respective knowledge champions can discuss the problems and issues in their strategic objectives and integrate Vision 2030.

Knowledge repository: This is a formal KM portal where all the knowledge documents, discussion forums, CoP presentations, and other assets are stored. It is possible that some documents will be confidential, contain financial and other information. Access to such documents is given as per access rules. Some policies and guidelines are needed that help users to upload their learning. (Inkinen, H.T., Kianto, A. \& Vanhala, M., 2015) Data analysis is an important part of the KM and Vision 2030 requirements. Each strategic objective should be supported by qualified data to help define priorities and dependencies.

Strategy implementation: The appropriate team will implement the Vision 2030 strategy. KM team is not involved in the strategy making or implementation. KM can store knowledge that helps in making informed decisions.

Measure success: Along the implementation, success should be measured as per the metrics defined. Knowledge Champions and CoP can discuss any shortcomings and help objectives that are lagging in performance. The KM dashboard presents a snapshot of the project progress and status of different strategic objectives. (Girard, J. \& Girard, J., 2015) 
Next sections present findings from a pilot semi-structured interview administered to experts in KM and IT systems. The model illustrated in Figure 1 is used as the starting point.

\section{Suggested Research Methodology}

The objective of the research is to assess the viability and suitability of the KM Vision 2030 model illustrated in Figure 1 and the answer the research objective posed in section 1. For this research, a pilot study in the form of a semi-structured instrument and a survey is designed and administered to respondents. Brennen (2017) is of the opinion that a well-structured semi-structured interview method can yield results when the questions focus on specific research areas, and when respondents know the subject. Subject-matter experts with deep knowledge in the process and methods of the research can provide insightful answers.

Silverman (2016) agrees with this opinion and further suggests that semi-structured interviews often serve as a pilot study for a larger survey. Respondents can give tips and guidance on strengthening the research. Agreeing to these points, Taylor et al. (2015) speak about the quality of respondents, their qualifications, and experience. The authors indicate that having a smaller number of expert respondents is beneficial rather than having a large cohort of uninformed respondents.

\subsection{Respondents}

Considering these inputs, a semi-structured instrument was designed with six open-ended questions and three close-ended, multiple-choice questions, single selection. Eleven experts from the private and public sector firms in Saudi Arabia were approached. These respondents had experience in multiple KM implementations in the private sector in Saudi Arabia and in Europe. They had deep knowledge of IT systems and implemented various IT projects. Out of these, five agreed to participate providing a sample size of five.

\subsection{Method of Administration}

The respondents were contacted by email and phone. The instrument was mailed to them along with the proposed model illustrated in Figure 1 and a request to answer the questions. Respondents answered the questions and mailed the completed instrument back.

\subsection{Method of Analysis}

The methodology suggested by Yandell (2017) was considered. Contextual and keyword analysis method was used. Responses for each question were noted down, and keywords, themes, and contexts were extracted. Common and differing issues from each response for a question were noted and cross-referencing used to analyse the results. Finally, the analysis is presented for each question with the extracted keywords, analysis, and assessment of responses.

\subsection{Design of Instrument}

\subsubsection{Semi-structured Survey}

The following open-ended questions were presented along with the research objective problem statement and the KM Vision 2030 model.

Q1. What are the barriers in measuring success indicators of Vision 2030?

Q2: How do you think that the KM Vision 2030 model will overcome these barriers?

Q3. Can you elaborate on the role of Knowledge Champions and CoPs in measuring KM success?

Q4. What role can the KM repository play in measuring the success of Vision 2030?

Q5. How can KM help to drive the success of Vision 2030?

Q6. What improvements are needed to enhance the KM Vision 2030 model to harvest big data and success indicators data?

The following close-ended question with multiple choices, single selection was designed. The instrument was presented to the same set of respondents along with the semi-structured instrument.

\subsubsection{Survey Instrument}

Respondents had to select only one option.

Q7. Greatest challenge to develop metrics for Vision 2030 is:

Integrating objectives 
Common measures

Qualitative metrics

Quantitative metrics

Q8. The challenges for metrics can be overcome by:

Pooling metrics

Common scales to link metrics

Weightage for metrics

Balanced Score Card

Q9. Challenge for big data analytics:

Verified data

Qualitative data

Quantitative data

Linking objectives

\section{Results of Analysis}

Analysis of responses for semi-structured interview and survey questions are given in this section.

\subsection{Responses for Semi-structured Interview}

The six questions designed in section 4.4.1 were posed to the respondents. Their responses were collected and analysed as per the method of analysis detailed in section 3.3.

\section{Q1. Barriers in measuring success indicators of Vision 2030}

Keywords from responses: 'too many objectives', 'no linking', 'no metrics', 'current data missing, 'economic impact metrics missing'.

Analysis: North and Kumta (2018) are of the opinion that an enterprise-wide KM includes many functions whose output is not measured in terms of revenue. In such cases, developing uniform metrics and the method of measuring the success is a barrier. In addition, when the functions and processes are disparate, then the best method is to develop common objectives. However, this becomes a problem when considering diverse processes with their own timelines and process owners and lack of a common framework.

Assessment: The analysis shows that the 97 strategic objectives detailed in section 1.2 are independent and linked to a specific pillar. Some of the objectives are implicit or explicit.

\section{Q2. How can KM Vision 2030 overcome the barriers?}

Keywords from responses: 'integrate objectives', 'develop common metrics', 'simulate impact', 'benchmark processes and metrics'.

Analysis: According to Wong et al. (2015) one of the problems in measuring the success of enterprise-wide KM implementations is to measure the revenue increase, projects completed, and other such metrics. In case of HR and support departments, linking the success to revenue is not feasible. Therefore, other metrics such as opportunities provided, areas facilitated and successfully launched, integrating practices and bringing them to the mainstream, and others are considered.

Assessment: From the above analysis and presentation in section 1.2, it is clear that the overall objective of Vision 2030 is to provide opportunities and develop the means to capitalise them. KM can bring together all the objectives, link them, and develop common metrics.

\section{Q3. Role of KM Champions and CoPs}

Keywords from responses: 'gather KM assets', 'drive KM', 'gather status reports', 'present findings,' spread KM mission.'

Analysis: Mohapatra et al. (2016) suggest that KM champions and CoPs are some of the main drivers in the KM practice. Whilst the main roles of these functions are to drive the KM initiative, they can be tasked with additional functions of assessing success as per the defined metrics. Since these entities have a wide reach through their 
departments and objectives, administering the metrics along the project life cycle is important. During meetings, they can present the metrics and streamline the project to achieve them.

Assessment: KM Champions need training on implementing metrics. CoP sessions can also include metrics analysis and measurement of KM success. Some reorientation is needed for the functions of these roles.

\section{Q4. Role of KM repository}

Keywords from responses: 'central role', 'link all objectives', 'common framework, 'metrics gathering and update', 'peer review.'

Analysis: Heisig et al. (2016) are of the opinion that KM serves as central repository where all KM assets uploaded. These assets are linked with a common framework, and clear workflows helps users to trace the nodes in the frameworks. Metrics to measure success and progress of all objectives can be made available through dashboard reports. Users can click on each entry and view the details. The KM manager needs to leverage the assets and involve all KM Champions and leaders, and facilitate peer review.

Assessment: KM portal needs to be designed to play a multifunctional role and facilitate learning as well as provide a central repository for metrics. KM Champions for each objective act as the drivers to encourage their departments to work towards meeting the metrics and measures.

\section{Q5. KM driving the success of Vision 2010}

Keywords from responses: 'uniting and bonding framework', 'connect disjointed and diverse entities, 'share knowledge and experience'.

Analysis: Kaivo-Oja et al. (2015) speak of KM more as an enabler and driver than a process or a tool. Involvement of the top management such as the Royal Prince or His Excellency gives an importance to the project. The 96 strategic objectives cover many diverse areas. KM tends to give a central framework that links these strategic objectives, brings them on the same board, and allows common themes, measures, and metrics of success to be defined. More importantly, it is essential to consider external benchmarks and information inflows that guide the practice.

Assessment: It is essential that the role and functions of KM Champions, CoPs, objective leaders, and strategic objectives domains need to be mapped out in the repository. Domains refer to areas such as logistics, tourism, etc. Another important aspect is the technology such as Microsoft SharePoint and others that can be used to build the KM portal.

\section{Q6. KM and Big Data}

Keywords from responses: 'big data analysis for objectives', 'current and desired status essential for metrics', 'KM should be data driven.'

Analysis: Khan and Vorley (2017) argue that KM practices must be implemented on qualified data that brings out the true status of the organisation. Data analysis is important since it helps to identify the behaviour of businesses and people in the economy, potential areas for growth, barriers for implementation, and visualise problems and opportunities, and this information can be used to measure the success of Vision 2030.

Assessment: From the analysis, it is important that the KM Vision 2030 must be based on connected data analysis. This means that dependencies of various objectives, factors that act as barriers and drivers, and benchmarks must be clearly defined. Unless a substantial amount of focussed data analysis is done, there is less scope for metrics for success to be defined.

\subsection{Responses for Survey}

The three questions designed in section 4.4.2 were posed to the respondents. Table 1 illustrates the responses. 
Table 1. Responses for survey

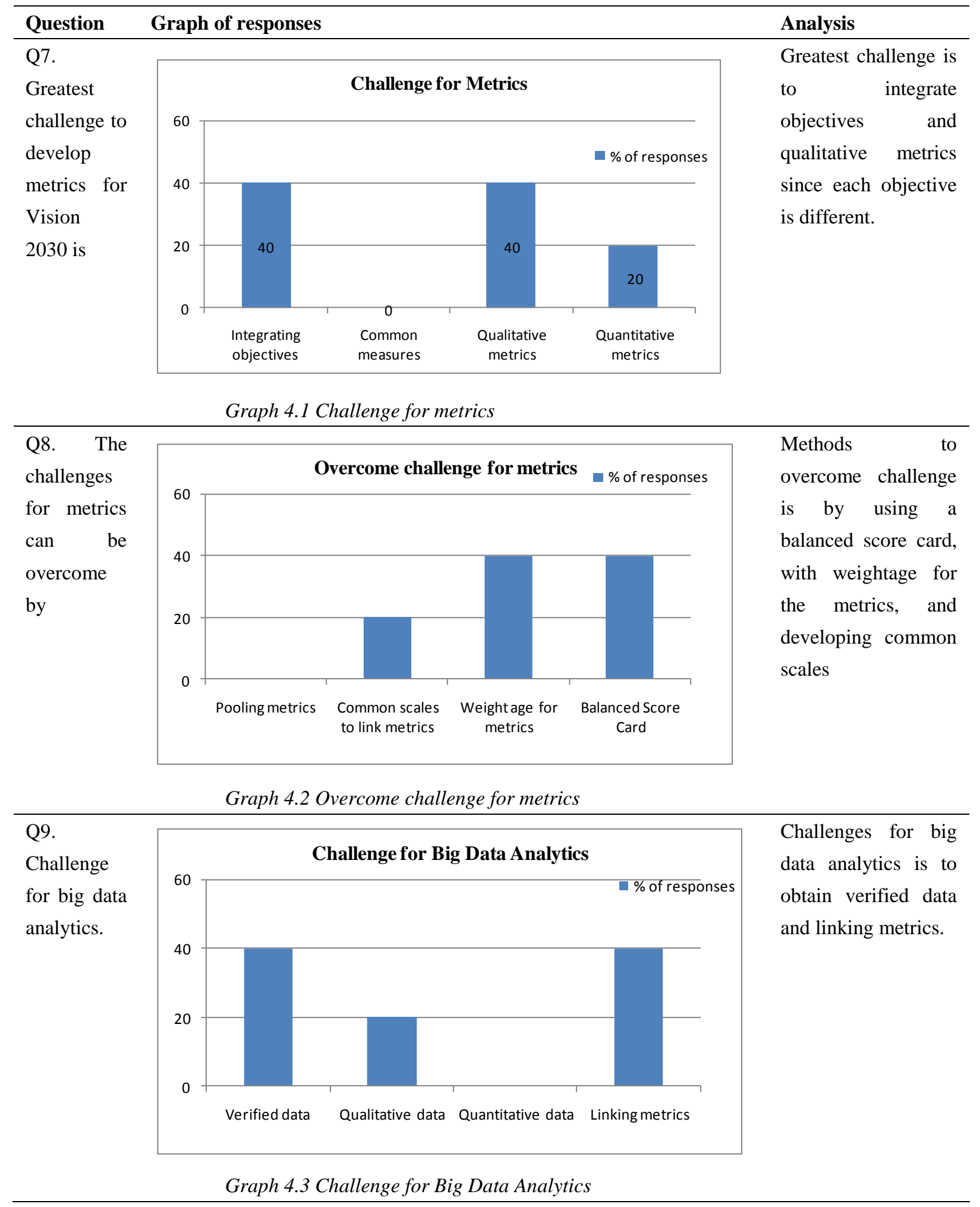

\section{Conclusions and Recommendations}

The previous sections carried out a literature review on KM and developed the Vision 2030 framework. A pilot study with semi-structured interview and survey instrument was designed and administered to five experts. The responses 
were analysed using key words analysis with cross references. The research objective examined was 'to develop a KM model that will help to measure the success indicators of Vision 2030'. The following conclusions are drawn.

- Vision 2030 is very challenging, since it considers 96 diversified and unconnected objectives that do not have a central and overarching framework.

- The KM 2030 model integrates all these objectives and acts as an enabler to help the project in measuring success based on common themes and metrics.

- The KM portal with the knowledge champions, CoP, user-driven document creation, and sharing has the potential to bind the whole project under a central platform accessible by all users.

- Big data analytics is essential for the project success since such an analysis would help to link data of all objectives, find the barriers and opportunities, define metrics, and help to measure success of Vision 2030.

\subsection{Recommendations}

Based on the analysis of results from section 4, the following actions are recommended. These can be implemented after discussions.

A consultation must be initiated with leaders of all the strategic objective leaders and their inputs obtained for the KM portal. Whilst an open design is needed, each objective should have its own link, with KM assets, plan with measures, and metrics. KM Champions and CoP must be developed from the early stages with each role and function trained to implement metrics and methods of measure. Big data analytics should be initiated with collating data on various objectives, the impact it has on the economy, and dependency on other initiatives.

It is essential to define the metrics for each objective and quantify the values, qualitative, and quantitative functions that determine success or failure. Once these metrics are known, then methods to measure the metrics along the life cycle of the objectives must run concurrently. KM portal should have a high level of interaction with users and include discussion forums, CoPs, and metrics. User involvement and cooperation of all strategic objective leaders is essential, and the top management must be directly involved, participate in key meetings, and sign off guidelines. The KM Vision 2030 Model can be further refined as the project progresses.

\subsection{Suggestions for Future Study}

The current research was a pilot study to design a proposed framework for a Vision 2030 KM Framework. The model and pilot study can be expanded to include a larger number of respondents for the semi-structured interview and survey, with an expanded list of questions. Results from these studies would help to refine the Vision 2030 KM Framework.

\section{References}

Brennen, B.S. (2017). Qualitative research methods for media studies. London: Routledge.

Chang, C.L.H., \& Lin, T.C. (2015). The role of organizational culture in the knowledge management process. Journal of Knowledge Management, 19(3), 433-455.

Fakir, I., \& Yerkes, S. (2018). Governance and the future of the Arab world. [Online] Carnegie Endowment. $\begin{array}{lllll}\text { Retrieved } & 13 & \text { October } & 2019, & \text { from }\end{array}$ https://carnegieendowment.org/2018/10/16/governance-and-future-of-arab-world-pub-77501

Geisler, E., \& Wickramasinghe, N. (2015). Principles of Knowledge Management: Theory, Practice, and Cases: Theory, Practice, and Cases. London: Routledge.

Girard, J., \& Girard, J. (2015). Defining knowledge management: Toward an applied compendium. Online Journal of Applied Knowledge Management, 3(1), 1-20.

Gupta, R., \& Singh, J. (2014). Knowledge Management and Innovation in (e) Government. International Journal of Information \& Computation Technology, 3(16), 1637-1645.

Heisig, P., Suraj, O.A., Kianto, A., Kemboi, C., Perez Arrau, G., \& Fathi Easa, N. (2016). Knowledge management and business performance: global experts' views on future research needs. Journal of Knowledge Management, 20(6), 1169-1198.

Hislop, D., Bosua, R., \& Helms, R. (2018). Knowledge management in organizations: A critical introduction. Oxford: Oxford University Press. 
Inkinen, H.T., Kianto, A., \& Vanhala, M. (2015). Knowledge management practices and innovation performance in Finland. Baltic Journal of Management, 10(4), 432-455.

Jansen, W. (2017). New business models for the knowledge economy. London: Routledge.

Kaivo-Oja, J., Virtanen, P., Jalonen, H., \& Stenvall, J. (2015). The effects of the internet of things and big data to organizations and their knowledge management practices. In International Conference on Knowledge Management in Organizations (pp. 495-513). Springer, Cham.

Khan, Z., \& Vorley, T. (2017). Big data text analytics: an enabler of knowledge management. Journal of Knowledge Management, 21(1), 18-34.

Misra, D.C., Hariharan, R., \& Khaneja, M. (2003). E-Knowledge Management Framework for Government Organizations. Information Systems Management, 20(2), 38-48.

Mohapatra, S., Agrawal, A., \& Satpathy, A. (2016). Designing knowledge management strategy. In Designing Knowledge Management-Enabled Business Strategies (pp. 55-88). Springer, Cham.

North, K., \& Kumta, G. (2018). Knowledge management: Value creation through organizational learning. Germany: Springer.

Nuruzzaman, M. (2018). Saudi Arabia's 'Vision 2030': Will It Save Or Sink the Middle East? [Online] E-International $\quad$ Relations. $\quad$ Retrieved $13 \quad$ October https://www.e-ir.info/2018/07/10/saudi-arabias-vision-2030-will-it-save-or-sink-the-middle-east/

Objectives. (2019). Vision 2030 Objectives and Road Map. [Online] Vision 2030. Retrieved 13 October 2019, from https://vision2030.gov.sa/sites/default/files/vision/Vision\%20Realization\%20Programs\%20Overview.pdf

Silverman, D. (2016). Qualitative research. London: Sage.

Taylor, S.J., Bogdan, R., \& DeVault, M. (2015). Introduction to qualitative research methods: A guidebook and resource. London: John Wiley \& Sons.

Tuwaijri, M.M. (2018). Towards Saudi Arabia's Sustainable Tomorrow and Vision 2030. [Online] United Nations. $\begin{array}{llll}\text { Retrieved } & 13 & \text { October } & 2019,\end{array}$ https://sustainabledevelopment.un.org/content/documents/20230SDGs_English_Report972018_FINAL.pdf

UAE. (2019). About UAE. [Online] Government of UAE. Retrieved 22 October 2019, from https://www.government.ae/en\#/

Vision 2030. Vision 2030 Kingdom of Saudi Arabia. [Online] Vision 2030. Retrieved 13 October 2019, from https://vision2030.gov.sa/download/file/fid/417

Webb, S.P. (2017). Knowledge management: Linchpin of change. London: Routledge.

Wong, K.Y., Tan, L.P., Lee, C.S., \& Wong, W.P. (2015). Knowledge management performance measurement: measures, approaches, trends and future directions. Information Development, 31(3), 239-257.

Yamazaki, R. (2012). Knowledge management for the public sector. Asian Productivity Organisation.

Yandell, B. (2017). Practical data analysis for designed experiments. London: Routledge.

\section{Notes}

Note 1. UAE. (2019). About UAE. [Online] Government of UAE. Available at https://www.government.ae/en\#/ [Accessed 22 October 2019].

Note 2. Objectives. 2019. Vision 2030 Objectives and Road Map. [Online] Vision 2030. Available at <https:/vision2030.gov.sa/sites/default/files/vision/Vision\%20Realization\%20Programs\%20Overview.pdf> [Accessed 13 October 2019].

Note 3. iBid, Jansen, 2017 